\title{
Dehydration-induced responses of primary photosynthetic processes and spectral reflectance indices in Antarctic Nostoc commune
}

\author{
Miloš Barták , Jana Hazdrová, Kateřina Skácelová ${ }^{\#}$, Josef Hájek
}

Department of Experimental Biology, Laboratory of Photosynthetic Processes, Faculty of Science, Masaryk University, University Campus - Bohunice, Kamenice 5, 62500 Brno, Czech Republic

\begin{abstract}
In this study, we investigated the relationship between relative water content (RWC) of $N$. commune colonies recorded during gradual dehydration and (i) normalized difference vegetation index (NDVI), (ii) photochemical reflectance index (PRI), and (iii) primary photochemical processes of photosynthesis, effective quantum yield of photosynthetic processes $\left(\Phi_{\text {PSII }}\right)$ in photosystem II particular. PRI increased from -0.05 to 0.02 with RWC decrease from $100 \%$ (full hydration) to $0 \%$ (dry state). NDVI showed somewhat curvilinear relationship with desiccation with minimum value of 0.25 found at $10 \%$ RWC. Negative effect of suprasaturation of $N$. commune colony with water on effective quantum yield $\left(\Phi_{\mathrm{PSII}}\right)$ was found at RWC range $80-100 \%$. At the RWC range, $\Phi_{\mathrm{PSII}}$ reached only $50 \%$ of maximum found at RWC of $30 \%$. In general, desiccation-response curve of showed polyphasic character with three main phases (phase I - constant $\Phi_{\text {PSII }}$ values, phase II - an increase with desiccation at RWC $80-30 \%$, and phase III sigmoidal decrease with desiccation at RWC 0-30\%). Non-photochemical quenching (qN) of absorbed light energy showed triphasic dependence on RWC as well. qN showed constant values in the phase I, an increase (phase II), and constant values at severe dehydration (phase III).
\end{abstract}

Key words: PRI, NDVI, Antarctic, James Ross Island, saturation effect, colony

DOI: $10.5817 / \mathrm{CPR} 2016-1-9$

Received October 2, 2015, accepted November 8, 2015.

*Corresponding author: Miloš Barták <mbartak@sci.muni.cz>

${ }^{\#}$ Recent address: Department of Botany, Faculty of Science, Charles University, Benátská 2, 12801 Praha 2, Czech Republic.

Acknowledgements: The authors thank the project CzechPolar (the Czech Ministry of Education, Sports and Youth) for providing field facilities and infrastructure for the research reported in this study. 


\section{Introduction}

Nostoc commune is frequently found in terrestrial and semi-aquatic Antarctic habitats. It is reported from maritime Antarctica (Victoria et al. 2013) as well as from continental Antarctica (e.g. Novis et Smissen 2006). Generally, the ability of $N$. commune to fix atmospheric nitrogen and, to resist desiccation may explain its dominance in many terrestrial habitats in Antarctica. In Antarctic ecosystems, such as margins of freshwater terrestrial lakes, temporal ponds, streams and seepages, rich in melt water during austral summer Nostoc commune typically forms colonies. Among Nostoc species forming sheetlike colonies, $N$. commune, and closely related $N$. flagelliforme are reported (Sand-Jensen 2014). At James Ross Island, Antarctica, N. commune colonies are quite abundant in shallow streams and seepages (Skácelová et al. 2013, Komárek et al. 2015).

$N$. commune colonies form inactive crusts when dry, but rapidly changes to gelatinous structures when wet (e.g. Novis et al. 2007). Major part of colonies are composed of the extracellular matrix - up to $60 \%$ of dry mass is reported (Hill et al. 1997). Matrix forms upper and lower surface of the colony as well as an intracolonial matter filling the space in between individual filaments of $N$. commune cells. The matrix is formed primarily of several polysaccharides (Rossi et Philippis 2015) that have a high viscosity and molecular weight (Sand-Jensen 2014). In general, $N$. commune matrix contains also monosaccharides, uronic acid, deoxy-sugars, pyruvate, acetate and peptides (Pereira et al. 2009). Physico-chemical properties of extracellular matrix may vary according to number and arrangement of exopolysaccharides. However, quantitative data on polysacharides in extracellular matrix are still insuffient for functional analysis of $N$. commune during wet-dry cycles. However, 1-4-linked xylogalactoglucan backbone with D-ribofuranose and 3-0-[(R)-
1-carboxyethyl]-D-glucuronic acidpendant groups are reported from desiccation tolerant $N$. commune (Helm et al. 2000).

$N$. commune is typical by a high tolerance to a great variety of environmental stressors including desiccation (Satoh et al. 2002, Tamaru et al. 2005). The species is considered extremely tolerant to long-term desiccation, some biomolecules may stay active even when rewetted after hundred years in dry state (Shirkey et al. 2000). During desiccation, several photoprotective mechanisms are activated in Nostoc. Among them, zeaxanthin, but also nostoxanthin and caloxanthin, and ketocarotenoids echinenone were detected in Nostoc $s p$. (Schagerl et Müller 2006) as well as carotenoids (Potts et al. 1987) and beta carotene that represents a strong photoprotective quenchers.

Photosynthetic processes in $N$. commune collonies from polar regions have been investigated by a variety of chlorophyll fluorescence techniques in response to light and temperature (Kosugi et al. 2010), UV-B radiation (Estêvāo 2015).

In this paper, we focused on changes in primary photosynthetic processes monitored by chlorophyll fluorescence parameters during desiccation in $N$. commune colony. We hypothesized that, similarly to cyanolichens (Lange et al. 1996), water suprasaturation effect resulting in inhibition of photosynthetic processes could be detected at high thallus hydration. We, therefore, also hypothesized that optimum hydration of $N$. commune colony would be less than full hydration, i.e. under $100 \%$ of relative water content. Simultaneously, we focused on changes in spectral reflectance indices NDVI and PRI. Similarly to the study of Yamano et al. (2006) who studied soil crusts. The letter one is associated with activation of xanthophyll-cycle pigments and studied in higher plants frequently. In lichens and cryptogamic polar autotrophs forming microbiological crusts, number of 
studies is limited. Recently, an interest in spectral reflectance properties of polar soil crust has been increased (see e.g. Walker et al. 2012), as well as ecophysiological characteristics, such as e.g. water holding capacity. The same trend is apparent also

\section{Material and Methods}

The colonies of Nostoc commune were collected in James Ross Island, Antarctica, from the long-term research plot located close to Czech Antarctic station J. G. Mendel ( $63^{\circ} 48^{\prime} 02^{\prime \prime} \mathrm{S}, 57^{\circ} 52^{\prime}$ 57" E). Sampling plot is typical by patchy moss cover (more than $50 \%$ of total plot area) with several lichen species (Barták et al. $2015 b$ ). The plot is wet at least for some part of austral summer season. It is supplied by melt water form two temporal streams originating in neighbouring annual snow field. Austral summer microclimate is typical by air temperature ranging from in the research of temperate zone ecosystems (Gypser et al. 2016). However, knowledge on physiological background of PRI changes in response to hydration status is still insufficient polar autotrophs.

$-10^{\circ} \mathrm{C}$ (monthly mean of September) to $6^{\circ} \mathrm{C}$ (monthly mean of February) - measured at $30 \mathrm{~cm}$ above surface (Láska et al. 2011). Austral summer surface temperature (absolute daily minimum, maximum) ranges from -7.1 to $12.0^{\circ} \mathrm{C}$ (Barták et Váczi 2014), and close-to-ground relative air humidity is found within the range of $80-100 \%$ (Láska et al. 2011). Dehydration response curves of PRI and NDVI were measured at J. G. Mendel station laboratory, while chlorophyll fluorescence parameters were measured after transfer to Brno, Czech Republic.

\section{Dehydration and spectral indices measurements}

Measurements of spectral reflectance indices and photosynthetic measurements were done in samples desiccating from fully hydrated to fully dry state in a laboratory (Mendel station). During the desiccation, room temperature was kept constant $\left(18^{\circ} \mathrm{C}, 40 \% \mathrm{RH}\right)$ and lichen thalli were left in open Petri dishes to desiccate

$\mathrm{RWC}(\%)=[(\mathrm{FM}-\mathrm{DM}) /(\mathrm{FW}-\mathrm{DM})] * 100$

where, FM, is the actual fresh mass (weight) of a sample, DM is the mass of fully dry sample, and $\mathrm{FW}$, is a mass of fully wet sample. From fully wet $(\mathrm{RWC}=$ $100 \%)$ to dry $(\mathrm{RWC}=0-10 \%)$ state of lichen thalli, NDVI and PRI were measured at specific hydration status. Normalized difference vegetation index (NDVI) was measured by PlantPen NDVI 300 (Photon System Instruments, Czech Republic). Pho- naturally desiccation. Relative water content (RWC) was evaluated before each single individual PRI, NDVI measurements using a gravimetric method. Samples were weighted on an analytical RADWAG scale (XA 60/220/X), and RWC calculated according to the equation:

Eqn. 1

tochemical reflectance index (PRI) was measured by a PlantPen PRI 200 (Photon System Instruments, Czech Republic). Both instruments use the below-specified spectral reflectance for calculation of the indices using the below equations 2 , and 3 . The NDVI, PRI data were then plotted against particular RWCs of individual species that was measured simultaneously. 


\section{Chlorophyll fluorescence}

Repetitive measurements of effective quantum yield ( $\left.\Phi_{\text {PSII }}\right)$ of photosystem II in Nostoc sp. started from fully wet state and ended in dry state. Samples were allowed to desiccate at room temperature $\left(\mathrm{t}=22^{\circ} \mathrm{C}\right.$, EEL laboratory, Brno, Czech Republic) and low irradiance $\left(20 \mu \mathrm{mol} \mathrm{m} \mathrm{m}^{-2} \mathrm{~s}^{-1}\right)$. During gradual slow-rate desiccation (according to sample size 7-14 h from fully wet to dry state), actual fresh mass (weight) $F_{M}$ was evaluated (Mettler AS100, Germany) as well as several chlorophyll fluorescence parameters using a PAM-2000 fluorometer (H.Walz, Germany): variable fluorescence at steady state $\left(\mathrm{F}_{\mathrm{S}}\right)$. The measurements were taken simultaneously so that the response of particular chlorophyll fluorescence parameters (see below) to RWC (Eqn. 1) could be evaluated. Light-adapted chlorophyll fluorescence comprised signals $\left(\mathrm{F}_{\mathrm{S}}, \mathrm{F}_{\mathrm{M}}{ }^{\prime}\right)$ and parameters $\left(\Phi_{\mathrm{PSII}}, \mathrm{qN}\right)$. They were measured each $20 \mathrm{~min}$. until dry state was reached.

\section{Results}

In $N$. commune, NDVI showed a curvilinear relationship to RWC with desiccation (see Fig. 1). Maximum values were found in the range of $40-70 \%$ RWC. Minimum NDVI of 0.12 (individual measure-

ment) was found at low RWC (0\%). PRI values exhibited an increase with desiccation (within a range from -0.02 to 0.01 ) with maximum found at RWC of $10 \%$.

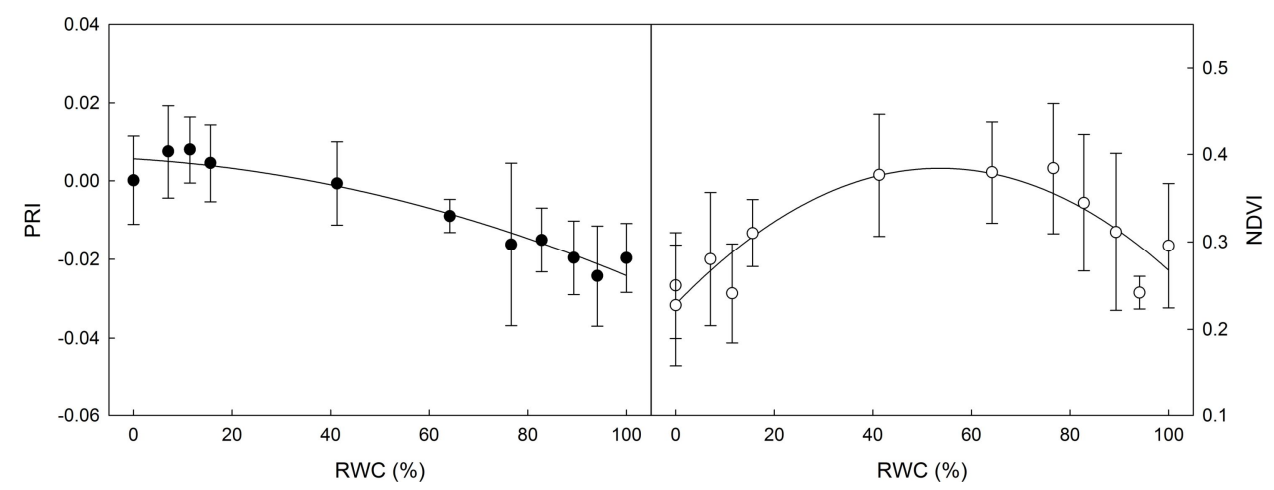

Fig. 1. Courses of PRI (left) and NDVI (right) in Nostoc sp. colony as dependent on relative water contents (RWC, \%) in a colony.

Dehydration-response curve of $\Phi_{\mathrm{PSII}}$ had polyphasic character with 3 main phases (Fig. 2). At RWC range $80-100 \%$
RWC (phase I), $\Phi_{\text {PSII }}$ was more or less constant $(0.15)$. With gradual dehydration (phase II) from RWC of 80 to $30 \%$, in- 
creased and showed a maximum of 0.27 at RWC of $30 \%$. Then, with further dehydration (phase III, RWC 0-30\%), N. commune colony showed a S-shaped decline in $\Phi_{\text {PSII }}$ with 0 found at RWC of about $5 \%$
RWC. Phase I with limited $\Phi_{\text {PSII }}$ could be related to reduction of the diffusive flux of dissolved inorganic carbon to the colony thanks to boundary layer thickness (SandJensen 2014).

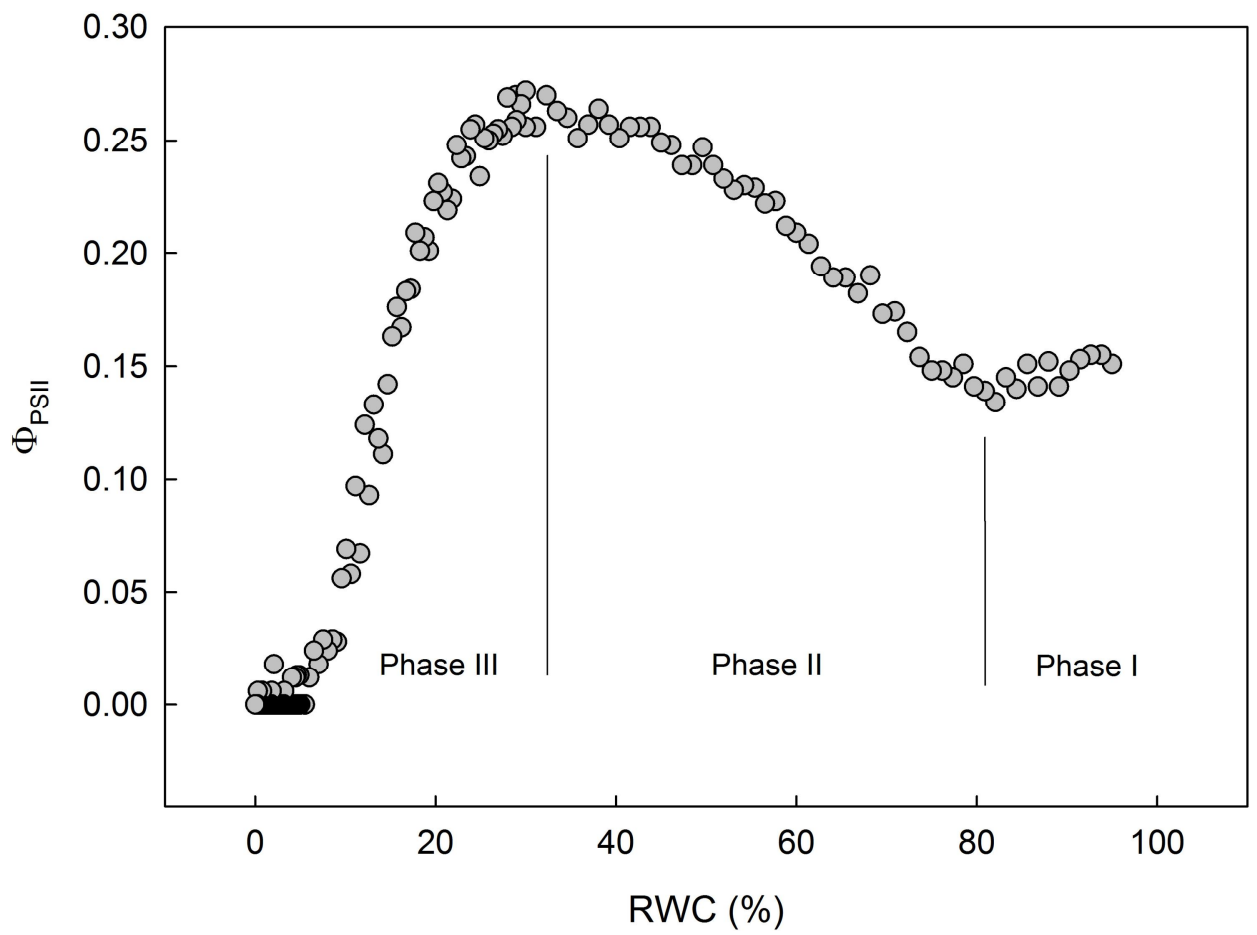

Fig. 2. Effect of gradual dehydration of Nostoc sp. colony (expressed as relative water content RWC decrease from 100-0\%) on effective quantum yield of PS II.

Variable fluorescence at steady state $\left(\mathrm{F}_{\mathrm{S}}\right)$ declined with desiccation in a polyphasic manner (see Fig. 3). It showed, however, constantly high values (about $0.730 \mathrm{mV}$ ) at RWC range of $79-100 \%$, and, at final phase of dehydration (RWC $0-17 \%)$, constantly low values $(0.160 \mathrm{mV})$. Non-photochemical quenching (qN) showed constant value at the RWC range (79$100 \%$ ), followed by an increase towards maximum (RWC 17-79\% corresponding to phase II in $\left.\Phi_{\text {PSII }}\right)$. Then, maxium $\mathrm{qN}$ of about 0.94 was maintained during following desiccation to fully desiccated state (from 17 to $0 \%$ RWC). Non-photochemical quenching ( $\mathrm{qN}$ ) of absorbed light energy showed constant value of about 0.7 at full hydration, then increased with following dehydration (RWC range of 79$100 \%$ ), and reached its maximum at RWC of $17 \%$ indicating that capacity of protective mechanisms in photosynthetic apparatus was fully exploited at the RWC. 


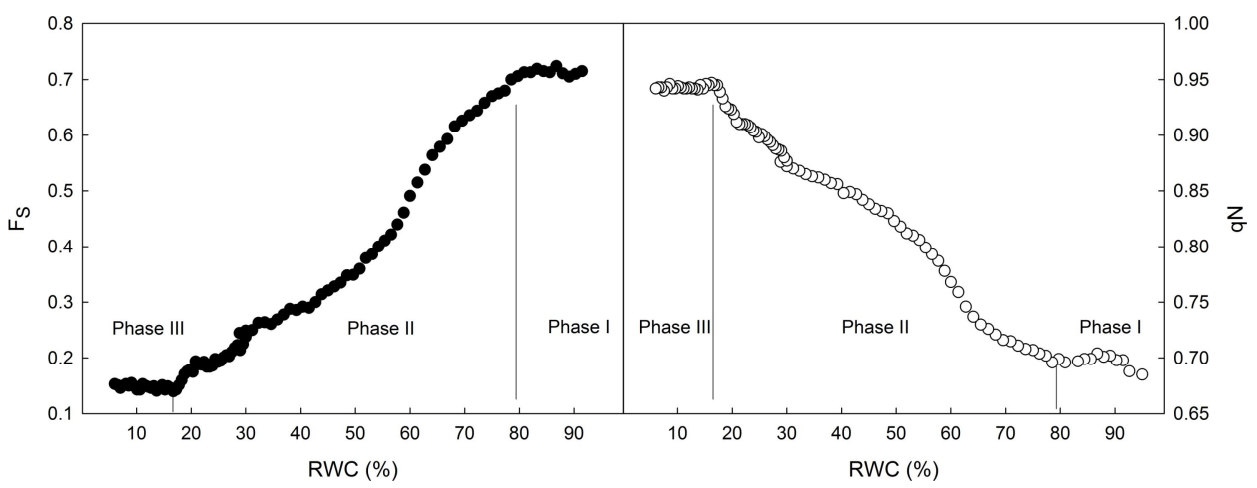

Fig. 3. Dehydration - response curves of steady-state chlorophyll fluorescence $\left(\mathrm{F}_{\mathrm{S}}\right.$, left), and nonphotochemical quenching (qN, right). Decrease in relative water content (RWC) from full hydration $(\mathrm{RWC}=100 \%)$ to desiccated state $(\mathrm{RWC}=0 \%)$ leads to a polyphasic decrease in $\mathrm{F}_{\mathrm{S}}$, and an increase in $\mathrm{qN}$.

\section{Discussion}

A polyphasic curve of $\Phi_{\text {PSII }}$ to RWC relationship reflects several limitations of photosynthetic processes in $N$. commune colony. Initial phase of desiccation (WP range 100 to $80 \%$ ), at which $\Phi_{\mathrm{PSII}}$ values are constant but far below their maximum, is attributed to photosynthesis exploiting carbon available inside Nostoc cells thanks to carbon concentrating mechanisms exclusively. At this RWC range no atmospheric carbon contribute to photosynthetic processes thank to a physical barrier of water-saturated colony for $\mathrm{CO}_{2}$ diffusion. Such phenomenon is called suprasaturation (i.e. the photosynthetizing poikilohydric organism contains more water than necessary to saturate photosynthesis) and well described for lichens (see e.g. Lange et al. 1996, 2001). In the following phase (RWC from 80 to $30 \%$ ), the atmospheric $\mathrm{CO}_{2}$ diffusion into the colony is enhanced and an increased $\Phi_{\text {PSII }}$ can be explained as a coaction of increased $\mathrm{CO}_{2}$ intake and fixation by the colony (when considering an equilibrium between photochemical and biochemical processes). The fall of $\Phi_{\mathrm{PSII}}$ in the last RWC range (WP decreasing from
30 to $0 \%$ ) is associated dehydration-decline in photosynthesis in Nostoc cells.

Our results showing a steep $\Phi_{\mathrm{PSII}}$ decline at RWC below $20 \%$ suggest that even a partially hydrated Nostoc commune colony is capable to maintain high rates of photosynthetic processes in desiccating colonies. This conclusion might be supported by the data presented by Kvíderová et al. (2011), who reported unchanged $\mathrm{F}_{\mathrm{V}} / \mathrm{F}_{\mathrm{M}}$ and $\Phi_{\mathrm{PSII}}$ for at least $6 \mathrm{~h}$ from the start of desiccation. Similar rate is reported for rehydration, Gupta et Kashyap (1995) showed that water uptake by desiccated thalli of $N$. commune occurring in Schirmacher Oasis (Antarctica) took about 5 hours for the thalli to absorb water to a saturating level. In the field, however, desiccation rate and gradual loss of photosynthetic activity is even slower than reported by Kvíderová et al. (2011) because of contact of the colonies with wet surfaces such as e.g. soil, mosses. Such contact allows to slow down desiccation and prolong the time of photosynthetic activity. In the field, size of $N$. commune colony may play a role since a faster desiccation 
in small-area colonies is reported (Gao et Ai 2004). It has been demonstrated earlier that Nostoc colonies decrease their mean diameter from $150-250 \mu \mathrm{m}$ to $50-100 \mu \mathrm{m}$ during desiccation from wet to dry state (Belnap et Gardner 1993). Apart of colony size, a 3-D complexity of colony may affect the rate of desiccation as well. Typically, surface to volume ratio and morphological structures (Esseen et al. 2015) may affect water holding capacity and the rate of desiccation.

Decrease of $\mathrm{F}_{\mathrm{S}}$ and an increase in $\mathrm{qN}$ is a general phenomenon found in desiccating poikilohydric autotrophs. Such phenomenon is a mechanism providing effective protection of photosynthetic apparatus. For terrestrial cyanobacteria, numerous pigments, carotenoids in particular (Vincent et al. 1993, Lakatos et al. 2001), and other quenchers, such as e.g. inhibition of state 2 to state 1 transition (Trnková et Barták 2016, accepted), are involved into the protection during desiccation, which, together with fast reactivation of photosynthetic pigments (Abed et al. 2014) and lipids resynthesis after wetting (Taranto et. al.
1993), represent a strategy to cope with repeated drought stress. Specifically for $N$. commune, these mechanisms make the species extremely desiccation and photoinhibition tolerant (Fukuda et al. 2008).

Optimum RWC at which maximum NDVI was reached ranged $40-60 \%$. The RWC range is well comparable to the values reported in our earlier studies (similarly to Barták et al. (2015a), Trnková et Barták 2016, accepted). NDVI index might be affected by phycocynine since spectral reflectances between 610 and $650 \mathrm{~nm}$ are included into PC index (see e.g. Kutser et al. 2006). PRI exhibited negative values at RWC range $40-100 \%$. It means that wellhydrated Nostoc sp. colony has lower reflection at 570 than $531 \mathrm{~nm}$. Possible explanation is an interaction with absorption spectra of phycobilisomes (phycoerythrin, phycocyanin) that overlap at the wavelength about $570 \mathrm{~nm}$ (Singh et al. 2015). Similarly, recent study of Li et al. (2015) indicated a decrease in reflectance $570 \mathrm{~nm}$ in cyanobacterial community and attributed the decrease to absorption by phycoerythrin.

\section{References}

Abed, R. M. M., Polerecky, L., Al-Habsi, A., Oetjen, J., Strous, M. and De Beer, D. (2014): Rapid recovery of cyanobacterial pigments in desiccated biological soil crusts following addition of water. PLOS ONE 9 (11): e112372. doi: 10.1371/journal.pone.0112372.

Barták, M., Hazdrová, J., SkÁcelová, K., TrnkovÁ, K., VÁczi, P. and HáJeK, J. (2015a): Resistance of Antarctic Nostoc sp. colonies to dehydration assessed by chlorophyll fluorescence parameters and spectral reflectance. In: Book of Abstract, $6^{\text {th }}$ International Conference on Polar and Alpine Microbiology, České Budějovice.

BARTÁK, M., VÁCZI, P. (2014): Long-term fluorometric measurements of photosynthetic processes in Antarctic moss Bryum sp. During austral summer season. Czech Polar Reports, 4: 63-72.

BARTÁK, M., VÁCZI, P., StAChOŇ, Z. and KubeŠOVÁ, S. (2015b): Vegetation mapping of mossdominated areas of northern part of James Ross Island (Antarctica) and a suggestion of protective measures. Czech Polar Reports, 5: 75-87.

Belnap J., GARDNER J. S. (1993): Soil microstructure in soils of the Colorado Plateau: The role of the cyanobacterium Microcoleus vaginatus. Great Basin Naturalist, 53: 40-47.

Esseen, P-A., Olsson, T., Coxson, D. and GauslaA, Y. (2015): Morphology influences water storage in hair lichens from boreal forest canopies. Fungal Ecology, 18: 26-35, http://dx.doi.org/10.1016/j.funeco.2015.07.008. 
EstÊVĀO, D. M. M. (2015): Production of UV-B screens and changes in photosynthetic efficiency in Antarctic Nostoc commune colonies and a lichen Xanthoria elegans depend on a dose and duration of UV-B stress. Czech Polar Reports, 5: 55-68.

Fukuda, S., Yamakawa, R., Hirai, M., Kashino, Y. Koike, H. and Satoh, K. (2008): Mechanisms to avoid photoinhibition in a desiccation-tolerant cyanobacterium, Nostoc commune. Plant and Cell Physiology, 49 : 488-492.

GAO, K., AI, H. (2004): Relationship of growth and photosynthesis with colony size in an edible cyanobacterium, Ge-Xian-Mi Nostoc (Cyanophyceae). Journal of Phycology, 40: 523-526.

GuPTA, R. K., KASHYAP, A. K. (1995): Water uptake and loss by Antarctic cyanobacterium Nostoc commune. Eleventh Indian Expedition to Antarctica, Scientific Report, Department of Ocean Development, Technical Publication No. 9, pp. 221-227.

Gypser, S., Veste, M.,Thomas, Fischer, T. and Lange, P. (2016): Infiltration and water retention of biological soil crusts on reclaimed soils of former open-cast lignite mining sites in Brandenburg, north-east Germany. Journal of Hydrology and Hydromechanics, 64: 1-11.

Helm, R.F., Huang, Z., Edwards, D., Leeson, H., Peery, W. and Potts, M. (2000): Structural Characterization of the Released Polysaccharide of Desiccation-Tolerant Nostoc commune DRH-1. Journal of Bacteriology, 182: 974-982.

Hill, D. R., Keenan, T.W., Helm, R.F., Potts, M., Crowe, L.M. and Crowe, J.H. (1997): Extracellular polysaccharide of Nostoc commune (Cyanobacteria) inhibits fusion of membrane vesicles during desiccation. Journal of Applied Phycology, 9: 237-248.

KomÁReK, J., GenuÁrio, G.B., FioRe, M. F. and Elster, J. (2015): Heterocytous cyanobacteria of the Ulu Peninsula, James Ross Island, Antarctica. Polar Biology, 38: 475-492.

Kosugi, M., Katashima, Y., Aikawa, S. and Satoh, K. (2010): Comparative study on the photosynthetic properties of Prasiola (Chlorophyceae) and Nostoc (Cyanophyceae) from Antarctic and non-antarctic sites. Journal of Phycology, 46: 466-476.

Kutser, T., MetsamaA, L., Strömbeck, N. and Vahtmäe, E. (2006): Monitoring cyanobacterial blooms by satellite remote sensing. Estuarine, Coastal and Shelf Science, 67: 303-312.

KVÍDEROVÁ, J., ElSTER, J. and ŠIMEK, M. (2011): In situ response of Nostoc commune s.l. colonies to desiccation in Central Svalbard, Norwegian High Arctic. Fottea, 11: 87-97.

Lakatos, M., Bilger, W. and Büdel, B. (2001): Carotenoid composition of terrestrial Cyanobacteria: response to natural light conditions in open rock habitats in Venezuela. European Journal of Phycology, 36: 367-375.

Lange, O.L., Green, T.G.A., Reichenberger, H. and Meyer, A. (1996): Photosynthetic depression at high thallus water contents in lichens: Concurrent use of gas exchange and fluorescence techniques with a cyanobacterial and a green algal Peltigera species. Botanica Acta, 109: 43-50.

Lange, O. L., Green, T. G. A. and Heber, U. (2001): Hydration-dependent photosynthetic production of lichens: what do laboratory studies tell us about field performance? Journal of Experimental Botany, 52: 2033-2042.

Láska, K., Barták, M., Hájek, J., Prošek, P. and Bohuslavová, O. (2011): Climatic and ecological characteristics of deglaciated area of James Ross Island, Antarctica, with a special respect to vegetation cover. Czech Polar Reports, 1: 49-62.

Li, L., Li, L. and Song, K. (2015): Remote sensing of freshwater cyanobacteria: An extended IOP Inversion Model of Inland Waters (IIMIW) for partitioning absorption coefficient and estimating phycocyanin. Remote Sensing of Environment, 157: 9-23.

Novis, P.M., SMissen, R.D. (2006): Two genetic and ecological groups of Nostoc commune in Victoria Land, Antarctica, revealed by AFLP analysis. Antarctic Science, 18: 573-581.

Novis, P. M., Whitebread, D., Gregorich, E. G., Hunt, J.E., Sparrow, A.D., Hopkins, D.W., ELBERLiNG, B. and GREENFIELD, L.G. (2007): Annual carbon fixation in terrestrial populations of Nostoc commune (Cyanobacteria) from an Antarctic dry valley is driven by temperature regime. Global Change Biology, 13: 1224-1237.

Pereira, S., Zille, A., Micheletti, E., Moradas-Ferreira, P., De Philippis, R. and Temagnini, P. (2009): Complexity of cyanobacterial exopolysaccharides: composition, structures, including 
factors of putative genes involved in their biosynthesis and assembly. FEMS Microbiology Reviews, 33: 917-941.

Potts, M., Olie, J. J., Nickels, J. S., Parsons, J. and White, D. C. (1987): Variation in phospholipid ester-linked fatty acids and carotenoids of desiccated Nostoc commune (cyanobacteria) from different geographic locations. Applied and Environmental Microbiology, 53: 4-9.

Rossi, F., DE PhILIPPIS, R. (2015): Role of Cyanobacterial Exopolysaccharides in Phototrophic Biofilms and in Complex Microbial Mats. Life, 5: 1218-1238.

Satoh, K., Hirai, M., Nishio, J., Yamaji, T., Kashino, Y. and Koike, H. (2002): Recovery of photosynthetic systems during rewetting is quite rapid in a terrestrial cyanobacterium, Nostoc commune. Plant and Cell Physiology, 43:170-176.

SAND-JENSEN, K. (2014): Ecophysiology of gelatinous Nostoc colonies: unprecedented slow growth and survival in resource-poor and harsh environments. Annals of Botany, 114: 17-33.

SCHAGERL, M., MüLLER, B. (2006): Acclimation of chlorophyll a and carotenoid levels to different irradiances in four freshwater cyanobacteria. Journal of Plant Physiology, 163: 709-716.

Shirkey, B., Kovarcik, D. P., Wright, D. J., Wilmoth, G., Prickett, T. F., Helm, R. F., Gregory, E. M. and PotTs, M. (2000): Active Fe-containing superoxide dismutase and abundant sodF mRNA in Nostoc commune (Cyanobacteria) after years of desiccation. Journal of Bacteriology, 182:189-197.

Singh, N. K., Sonani, R. R., Rastogi, R. P. and Madamwar, D. (2015): The Phycobilisomes: An Early Requisite for Efficient Photosynthesis in Cyanobacteria. EXCLI Journal, 14: 268-89.

SkÁcelovÁ, K., BARTÁK, M., Coufalík, P., NÝvlt, D. and TrnkovÁ, K. (2013): Biodiversity of freshwater algae and cyanobacteria on deglaciated northern part of James Ross Island, Antarctica. A preliminary study. Czech Polar Reports, 3: 93-106.

TAmaru, Y., TAKani, Y., Yoshida, T. and SAKAmoto, T. (2005): Crucial role of extracellular polysaccharides in desiccation and freezing tolerance in the terrestrial cyanobacterium Nostoc commune. Applied and Environmental Microbiology (AEM), 71: 7327-7333.

TARAnto, P. A., KeEnan, T. W. and PotTs, M. (1993): Rehydration induces rapid onset of lipid biosynthesis in desiccated Nostoc commune (Cyanobacteria). Biochimica et Biophysics Acta, 1168: 228-237.

TRNKOVÁ, K., BARTÁK, M. (2016): Desiccation-induced changes in photochemical processes of photosynthesis and spectral reflectance in Nostoc commune (Cyanobacteria, Nostocales) colonies from polar regions. Phycological Research, accepted.

Victoria, de F. C., Albuquerque, de M. P., Pereira, A. B., Simas, F. N. B., Spielmann, A. A. and Schaefer, C.E.G.R. (2013): Characterization and mapping of plant communities at Hennequin Point, King George Island, Antarctica. Polar Research, 32, 19261, http://dx.doi.org/10.3402/polar.v32i0.19261.

Vincent, W., Downes, M.T., Castenholz, R.W. and Howard-Williams, C. (1993): Community structure and pigment organisation of cyanobacteria-dominated microbial mats in Antarctica. European Journal of Phycology, 28: 213-221.

Walker, D. A., Timling, I., Frost, S. M., Matyshak, G. V., Frost, G. V., Epstein, H. E., Zhurbenko, M. and Afonina, O. (2012): High cover, biomass and NDVI of biological soil crusts on Hayes Island, Franz Josef Land, Russia. Book of Abstracts, the $10^{\text {th }}$ International Conference on Permafrost, Salekhard, Russia, 25-29 June 2012.

Yamano, H., Chen, J., Zhang, Y. and TAmuRA, M. (2006): Relating photosynthesis of biological soil crusts with reflectance: preliminary assessment based on a hydration experiment. International Journal of Remote Sensing , 27 :5393-5399. 